\title{
Valvuloarterial impedance - parameter of overall load in aortic stenosis and hypertension
}

\author{
Dunja Klepo ${ }^{1 *}$, Jure Mirat ${ }^{2}$ \\ ${ }^{1}$ Clinical Hospital Center Osijek, Osijek, Croatia \\ ${ }^{2}$ Faculty of Medicine Josip Juraj Strossmayer University of Osijek, Croatia
}

Background: It has been reported that $30-40 \%$ of patients with aortic stenosis (AS) are hypertensive. The presence of hypertension can affect decision making in patients with AS, hence it could be valuable to consider alternative ultrasonographic measurments. Valvulo-arterial impedance $\left(z_{v a}\right)$ is a parameter of overall load, obtained by summation of valvular and vascular load. Valvular component of pressure overload is caused by an obstruction on the stenosed aortic valve level. Vascular component of the load occurs because of the systemic vascular resistence increase caused by hypertension. $Z_{\mathrm{va}}$ is superior to the standard indexes of aortic stenosis severity in predicting left ventricle (LV) dysfunction.

Aim: We tried to determine the influence of valvular and peripheral stress on the LV wall in patients with coexisting aortic stenosis and hypertension.

Patients and Methods: This study included 18 consecutive patients ( 11 male and 7 female). These patients were divided into four strata: patients with aortic stenosis and hypertension $(\mathrm{AS}+\mathrm{H})$, patients with aortic stenosis (AS), patients with hypertension $(\mathrm{H})$ and control group $(\mathrm{N})$.

Results: After computing $\mathrm{z}_{\mathrm{va}}$, the highest average value was found in the $A S+H$ stratum $\left(z_{v a}=7,46 \mathrm{mmHg} / \mathrm{ml} / \mathrm{m}^{2}\right)$. Average $z_{v a}$ values in AS stratum $\left(z_{v a}=5,78 \mathrm{mmHg} / \mathrm{ml}^{2} / \mathrm{m}^{2}\right)$ and $\mathrm{H}$ stratum $\left(\mathrm{z}_{\mathrm{va}}=4,75 \mathrm{mmHg} / \mathrm{ml} / \mathrm{m}^{2}\right)$ were reduced in comparison to $\mathrm{AS}+\mathrm{H}$ stratum. In the $\mathrm{N}$ stratum we found the lowest average $\mathrm{z}_{\mathrm{va}}$ value, $\mathrm{z}_{\mathrm{va}}=3,85 \mathrm{mmHg} / \mathrm{ml} / \mathrm{m}^{2}$. In addition to $z_{\mathrm{va}}$, we also calculated systemic arterial compliance (SAC) in all strata. SAC is a measure of peripheral arterial load as a result of arterial system thickening, caused by arterial hypertension. After calculating average SAC values for all strata, we established the following results: the lowest average $\mathrm{SAC}$ values were in the $\mathrm{AS}+\mathrm{H}$ stratum, $\mathrm{SAC}=0,43$ $\mathrm{ml} / \mathrm{m}^{2} / \mathrm{mmHg}$, in the AS stratum the average SAC value was lower, $\mathrm{SAC}=0,62 \mathrm{ml} / \mathrm{m}^{2} / \mathrm{mmHg}$, and in the $\mathrm{H}$ and $\mathrm{N}$ stratum, the average $S A C$ value was equal $\left(S A C=0,73 \mathrm{ml} / \mathrm{m}^{2} /\right.$ $\mathrm{mmHg}$ ).

Conclusion: Hypertension creates an excessive LV hemodynamic load on valvular load caused by aortic stenosis. We also determined that systemic arterial compliance in double load decreases in regards to individual compliances measured in patients with aortic stenosis and hypertension.

KEYWORDS: aortic stenosis, arterial hypertension, valvuloarterial impedance, compliance.

Received: $20^{\text {th }}$ Mar 2013

*Address for correspondence: Clinical Hospital Center Osijek, J. Huttlera 4, HR31000 Osijek, Croatia.

Phone: +385-31-511-511

E-mail: dklepo@mefos.hr

\section{Literature}

1. Briand M, Dumesnil JG, Kadem L, Tongue AG, Rieu R, Garcia D, et al. Reduced systemic arterial compliance impacts significantly on left ventricular afterload and function in aortic stenosis. J Am Coll Cardiol. 2005;46;291-8.

2. Hachicha Z, Dumesnil JG, Pibarot P. Usefulness of the valvuloarterial impedance to predict adverse outcome in asymptomatic aortic stenosis. J Am Coll Cardiol. 2009;54: 100311.

3. Antonini-Canterin F, Huang G, Cervesato E, Faggiano P, Pavan D, Piazza R, et al. Symptomatic aortic stenosis. Does systemic hypertension play an additional role? Hypertension. 2003;41:1268-72. 